\title{
Meminimalkan Sisa Pemotongan Besi Beton dalam Proyek Konstruksi
}

\author{
Bambang Santoso ${ }^{1}$, Sofyan Mufti Prasetiyo ${ }^{2}$, Agung Wijoyo ${ }^{3}$ \\ ${ }^{1,2,3}$ Program Studi Teknik Informatika, Universitas Pamulang \\ Jln. Surya Kencana No. 1 Pamulang, Tangerang Selatan, Banten, Indonesia \\ e-mail: $\left\{{ }^{1}\right.$ dosen01692, ${ }^{2}$ dosen01809, ${ }^{3}$ dosen01671 $\} @$ unpam.ac,id
}

\begin{abstract}
Construction industries are a must in developing countries. Constructions take part in almost every corner of the country. In construction projects, reinforced concrete plays big part in any construction. A long bar of steel are cut into be several lengths to satisfy the requirements of the buildings to be build. In this process, waste cannot be avoided. And the waste of steel bar is very destructive to environment. This research is to find a way to minimize the waste in the process of cutting steel bars. The algorithm used is Greedy Search. Greedy Search is where the optimized solution in every step is taken, in the hope that the overall solution will be optimized for the problem. Optimized solution here is the minimum waste by the steel bar cutting. This will minimize the cost by the construction companies and at the same time preserve the environment.
\end{abstract}

Keywords: minimize waste, greedy search, optimized solution, construction project, cutting stock problems.

\section{Pendahuluan}

Di negara maju maupun negara berkembang, pembangunan tidak bisa terlepas dari proyek konstruksi baik berupa gedung, jalan, jembatan atau lainnya. Dalam banyak hal, bangunan ditopang oleh beton bertulang. Pembuatan beton bertulang membutuhkan besi beton dengan panjang yang beragam. Besi beton dibeli dalam panjang yang sama. Kemudian dipotong-potong sesuai kebutuhan yang diperlukan konstruksi.

Dalam memotong besi beton, banyak terjadi sisa potongan yang terlalu pendek untuk digunakan. Sisa ini akan dibuang dan menjadi sampah. (Abuhassan \& Nasereddin, 2011) Sampah besi beton ini akan mencemari lingkungan dan sangat lama untuk dihancurkan oleh alam. Di samping itu, sisa yang banyak akan menambah ongkos produksi.

Penelitian ini mencoba menjawab masalah tersebut dengan memakai algoritma Greedy Search. Pemotongan besi beton yang efektif akan meminimalkan sampah besi. Ini pada gilirannya akan membantu memperbaiki lingkungan, di samping mengurangi ongkos produksi.

\section{Metodologi}

\section{Kebutuhan Besi Beton Dalam Konstruksi}

Contoh kebutuhan untuk konstruksi adalah sebagai berikut.
Tabel 1 Kebutuhan besi konstruksi

\begin{tabular}{|c|c|c|c|}
\hline Diameter & Item & Panjang & Banyaknya \\
\hline $10 \mathrm{~mm}$ & 1 & $1.9 \mathrm{~m}$ & 200 \\
\hline & 2 & $2.2 \mathrm{~m}$ & 150 \\
\hline & 3 & $2.7 \mathrm{~m}$ & 100 \\
\hline & 4 & $3.1 \mathrm{~m}$ & 200 \\
\hline $13 \mathrm{~mm}$ & 1 & $2,1 \mathrm{~m}$ & 220 \\
\hline & 2 & $3,5 \mathrm{~m}$ & 180 \\
\hline & 3 & $5,4 \mathrm{~m}$ & 170 \\
\hline & 4 & $6,1 \mathrm{~m}$ & 140 \\
\hline & 5 & $6,8 \mathrm{~m}$ & 130 \\
\hline
\end{tabular}

Kebutuhan satu tipe besi tidak dapat digantikan dengan tipe besi beton lain. Misal tipe $10 \mathrm{~mm}$ tidak dapat digantikan dengan tipe $13 \mathrm{~mm}$. Maka untuk penelitian, dapat diambil hanya satu tipe saja. Area tipe 1 dan tipe 2 akan selalu terpisah satu sama lain.

Panjang besi beton standar adalah 12 meter. Dengan keperluan konstruksi beragam, besi ini harus dipotong-potong agar sesuai kebutuhan.

Untuk ini, perencanaan diperlukan untuk pemotongan besi beton. Perencanaan ini harus menjawab dua pertanyaan:

1. Bagaimana pola pemotongan yang harus dilakukan untuk setiap batang besi beton?

2. Berapa batang besi beton yang harus dibeli untuk memenuhi seluruh keperluan konstruksi? 


\section{Pemilihan Metode}

Cara terbaik dalam pencarian cara memotong besi adalah dengan metode Brute Force. Dengan Brute Force, seluruh kemungkinan diperiksa satu per satu dan dicari solusi optimal. Cara ini terbaik dan dijamin menghasilkan solusi optimal, tapi membutuhkan waktu yang lama. Waktu yang diperlukan meningkat secara eksponesial mengikuti banyaknya variabel yang dipakai. (Feo \& Resende, 1995) (Wilt, Thayer, \& Ruml, 2010) Karenanya Brute Force sering ditinggalkan kecuali jika medan yang dipakai dipastikan sempit dan terbatas. Greedy Search adalah pendekatan cara lain yang akan dipakai di penelitian ini.

\section{Algoritma Greedy Search}

Algoritma didefinisikan sebagai prosedur dengan langkah-langkah berbatas untuk mencapai tujuan yang diharapkan. (Subhadra, 2016). Greedy Search (Pencarian Rakus) adalah algoritma dengan mengikuti penyelesaian masalah di mana dipilih nilai optimal lokal di setiap tahapan dengan harapan nanti akan mendapatkan hasil optimal secara global. Dalam beberapa kasus, strategi Pencarian Rakus tidak selalu mendapatkan hasil global optimal. Tapi secara umum, algoritma Pencarian Rakus dapat menghasilkan solusi optimal lokal yang mendekati hasil optimal global dengan waktu relatif singkat dan dengan banyak langkah yang bisa diprediksi.

Algoritma Pencarian Rakus mengandung dua sifat. (Malik, Sharma, \& Saroha, 2013)

1. Sifat pemilihan rakus: solusi global optimal dapat dicapai dengan membuat solusi lokal optimal. Dengan kata lain, solusi optimal dapat diperoleh dengan membuat pilihan rakus.

2. Sub struktur optimal: solusi optimal mengandung sub solusi optimal. Atau dengan kata lain, solusi optimal untuk suatu masalah adalah solusi optimal untuk sub masalah.

\section{Mencari Kombinasi}

Untuk mencari kombinasi pemotongan, dicari terlebih dahulu jumlah panjang maksimum kombinasi. Langkah yang dipakai adalah:

- Mencari panjang minimum kebutuhan.

- Membagi panjang besi (12 meter) dengan panjang minimum tersebut, hasil dibulatkan ke bawan

Misal untuk tabel 1 di atas, panjang minimum adalah 1,9 meter. Maka panjang kombinasi adalah $12 / 1,9=6$ (dibulatkan ke bawah). Ini disebut MaxCountItem.
Kemudian, dicari semua kombinasi yaitu sejumlah $\mathrm{C}(\mathrm{p}, \mathrm{m})$ di mana $\mathrm{p}=\mathrm{n}+$ MaxCountItem -1 dan $\mathrm{m}=\mathrm{n}-1$. Ini adalah kombinasi dengan pengulangan (Brualdi, 2010). Jumlah kombinasi $\mathrm{C}(\mathrm{p}, \mathrm{m})$ adalah

$$
\mathrm{C}(\mathrm{p}, \mathrm{m})=\mathrm{p} ! /(\mathrm{m} ! *(\mathrm{p}-\mathrm{m}) !)
$$

dengan $\mathrm{p} !=1 * 2 * 3 * \ldots * \mathrm{p}$

Dalam contoh tabel 1 di atas, kombinasi adalah $C(9,3)$. Jumlah item yang diinginkan $n=4$. Dengan MaxCountItem $=6$ maka $\mathrm{p}=9$ dan $\mathrm{m}=3$. Jumlah kombinasi $\mathrm{C}(9,3)$ adalah $9 ! /(3 ! * 6 !)=84$.

Tabel 1 Daftar Semua Kombinasi

\begin{tabular}{|c|c|c|c|c|c|c|c|c|}
\hline No & P1 & P2 & P3 & P4 & P5 & P6 & Tot & Ket. \\
\hline 1 & 1 & 1 & 1 & 1 & 1 & 1 & 11,4 & Valid \\
\hline 2 & 1 & 1 & 1 & 1 & 1 & 2 & 11,7 & Valid \\
\hline 3 & 1 & 1 & 1 & 1 & 1 & 3 & 12,2 & Tidak Valid \\
\hline 4 & 1 & 1 & 1 & 1 & 1 & 4 & 12,6 & Tidak Valid \\
\hline 5 & 1 & 1 & 1 & 1 & 2 & 2 & 12 & Valid \\
\hline 6 & 1 & 1 & 1 & 1 & 2 & 3 & 12,5 & Tidak Valid \\
\hline 7 & 1 & 1 & 1 & 1 & 2 & 4 & 12,9 & Tidak Valid \\
\hline 8 & 1 & 1 & 1 & 1 & 3 & 3 & 13 & Tidak Valid \\
\hline 9 & 1 & 1 & 1 & 1 & 3 & 4 & 13,4 & Tidak Valid \\
\hline 10 & 1 & 1 & 1 & 1 & 4 & 4 & 13,8 & Tidak Valid \\
\hline 11 & 1 & 1 & 1 & 2 & 2 & 2 & 12,3 & Tidak Valid \\
\hline 12 & 1 & 1 & 1 & 2 & 2 & 3 & 12,8 & Tidak Valid \\
\hline 13 & 1 & 1 & 1 & 2 & 2 & 4 & 13,2 & Tidak Valid \\
\hline 14 & 1 & 1 & 1 & 2 & 3 & 3 & 13,3 & Tidak Valid \\
\hline 15 & 1 & 1 & 1 & 2 & 3 & 4 & 13,7 & Tidak Valid \\
\hline 16 & 1 & 1 & 1 & 2 & 4 & 4 & 14,1 & Tidak Valid \\
\hline 17 & 1 & 1 & 1 & 3 & 3 & 3 & 13,8 & Tidak Valid \\
\hline 18 & 1 & 1 & 1 & 3 & 3 & 4 & 14,2 & Tidak Valid \\
\hline 19 & 1 & 1 & 1 & 3 & 4 & 4 & 14,6 & Tidak Valid \\
\hline 20 & 1 & 1 & 1 & 4 & 4 & 4 & 15 & Tidak Valid \\
\hline 21 & 1 & 1 & 2 & 2 & 2 & 2 & 12,6 & Tidak Valid \\
\hline 22 & 1 & 1 & 2 & 2 & 2 & 3 & 13,1 & Tidak Valid \\
\hline 23 & 1 & 1 & 2 & 2 & 2 & 4 & 13,5 & Tidak Valid \\
\hline 24 & 1 & 1 & 2 & 2 & 3 & 3 & 13,6 & Tidak Valid \\
\hline 25 & 1 & 1 & 2 & 2 & 3 & 4 & 14 & Tidak Valid \\
\hline 26 & 1 & 1 & 2 & 2 & 4 & 4 & 14,4 & Tidak Valid \\
\hline 27 & 1 & 1 & 2 & 3 & 3 & 3 & 14,1 & Tidak Valid \\
\hline 28 & 1 & 1 & 2 & 3 & 3 & 4 & 14,5 & Tidak Valid \\
\hline 29 & 1 & 1 & 2 & 3 & 4 & 4 & 14,9 & Tidak Valid \\
\hline 30 & 1 & 1 & 2 & 4 & 4 & 4 & 15,3 & Tidak Valid \\
\hline 31 & 1 & 1 & 3 & 3 & 3 & 3 & 14,6 & Tidak Valid \\
\hline 32 & 1 & 1 & 3 & 3 & 3 & 4 & 15 & Tidak Valid \\
\hline 33 & 1 & 1 & 3 & 3 & 4 & 4 & 15,4 & Tidak Valid \\
\hline 34 & 1 & 1 & 3 & 4 & 4 & 4 & 15,8 & Tidak Valid \\
\hline 35 & 1 & 1 & 4 & 4 & 4 & 4 & 16,2 & Tidak Valid \\
\hline 36 & 1 & 2 & 2 & 2 & 2 & 2 & 12,9 & Tidak Valid \\
\hline 37 & 1 & 2 & 2 & 2 & 2 & 3 & 13,4 & Tidak Valid \\
\hline 38 & 1 & 2 & 2 & 2 & 2 & 4 & 13,8 & Tidak Valid \\
\hline 39 & 1 & 2 & 2 & 2 & 3 & 3 & 13,9 & Tidak Valid \\
\hline 40 & 1 & 2 & 2 & 2 & 3 & 4 & 14,3 & Tidak Valid \\
\hline
\end{tabular}




\begin{tabular}{|c|c|c|c|c|c|c|c|c|}
\hline No & $\mathrm{P} 1$ & $\mathrm{P} 2$ & P3 & P4 & P5 & P6 & Tot & Ket. \\
\hline 41 & 1 & 2 & 2 & 2 & 4 & 4 & 14,7 & Tidak Valid \\
\hline 42 & 1 & 2 & 2 & 3 & 3 & 3 & 14,4 & Tidak Valid \\
\hline 43 & 1 & 2 & 2 & 3 & 3 & 4 & 14,8 & Tidak Valid \\
\hline 44 & 1 & 2 & 2 & 3 & 4 & 4 & 15,2 & Tidak Valid \\
\hline 45 & 1 & 2 & 2 & 4 & 4 & 4 & 15,6 & Tidak Valid \\
\hline 46 & 1 & 2 & 3 & 3 & 3 & 3 & 14,9 & Tidak Valid \\
\hline 47 & 1 & 2 & 3 & 3 & 3 & 4 & 15,3 & Tidak Valid \\
\hline 48 & 1 & 2 & 3 & 3 & 4 & 4 & 15,7 & Tidak Valid \\
\hline 49 & 1 & 2 & 3 & 4 & 4 & 4 & 16,1 & Tidak Valid \\
\hline 50 & 1 & 2 & 4 & 4 & 4 & 4 & 16,5 & Tidak Valid \\
\hline 51 & 1 & 3 & 3 & 3 & 3 & 3 & 15,4 & Tidak Valid \\
\hline 52 & 1 & 3 & 3 & 3 & 3 & 4 & 15,8 & Tidak Valid \\
\hline 53 & 1 & 3 & 3 & 3 & 4 & 4 & 16,2 & Tidak Valid \\
\hline 54 & 1 & 3 & 3 & 4 & 4 & 4 & 16,6 & Tidak Valid \\
\hline 55 & 1 & 3 & 4 & 4 & 4 & 4 & 17 & Tidak Valid \\
\hline 56 & 1 & 4 & 4 & 4 & 4 & 4 & 17,4 & Tidak Valid \\
\hline 57 & 2 & 2 & 2 & 2 & 2 & 2 & 13,2 & Tidak Valid \\
\hline 58 & 2 & 2 & 2 & 2 & 2 & 3 & 13,7 & Tidak Valid \\
\hline 59 & 2 & 2 & 2 & 2 & 2 & 4 & 14,1 & Tidak Valid \\
\hline 60 & 2 & 2 & 2 & 2 & 3 & 3 & 14,2 & Tidak Valid \\
\hline 61 & 2 & 2 & 2 & 2 & 3 & 4 & 14,6 & Tidak Valid \\
\hline 62 & 2 & 2 & 2 & 2 & 4 & 4 & 15 & Tidak Valid \\
\hline 63 & 2 & 2 & 2 & 3 & 3 & 3 & 14,7 & Tidak Valid \\
\hline 64 & 2 & 2 & 2 & 3 & 3 & 4 & 15,1 & Tidak Valid \\
\hline 65 & 2 & 2 & 2 & 3 & 4 & 4 & 15,5 & Tidak Valid \\
\hline 66 & 2 & 2 & 2 & 4 & 4 & 4 & 15,9 & Tidak Valid \\
\hline 67 & 2 & 2 & 3 & 3 & 3 & 3 & 15,2 & Tidak Valid \\
\hline 68 & 2 & 2 & 3 & 3 & 3 & 4 & 15,6 & Tidak Valid \\
\hline 69 & 2 & 2 & 3 & 3 & 4 & 4 & 16 & Tidak Valid \\
\hline 70 & 2 & 2 & 3 & 4 & 4 & 4 & 16,4 & Tidak Valid \\
\hline 71 & 2 & 2 & 4 & 4 & 4 & 4 & 16,8 & Tidak Valid \\
\hline 72 & 2 & 3 & 3 & 3 & 3 & 3 & 15,7 & Tidak Valid \\
\hline 73 & 2 & 3 & 3 & 3 & 3 & 4 & 16,1 & Tidak Valid \\
\hline 74 & 2 & 3 & 3 & 3 & 4 & 4 & 16,5 & Tidak Valid \\
\hline 75 & 2 & 3 & 3 & 4 & 4 & 4 & 16,9 & Tidak Valid \\
\hline 76 & 2 & 3 & 4 & 4 & 4 & 4 & 17,3 & Tidak Valid \\
\hline 77 & 2 & 4 & 4 & 4 & 4 & 4 & 17,7 & Tidak Valid \\
\hline 78 & 3 & 3 & 3 & 3 & 3 & 3 & 16,2 & Tidak Valid \\
\hline 79 & 3 & 3 & 3 & 3 & 3 & 4 & 16,6 & Tidak Valid \\
\hline 80 & 3 & 3 & 3 & 3 & 4 & 4 & 17 & Tidak Valid \\
\hline 81 & 3 & 3 & 3 & 4 & 4 & 4 & 17,4 & Tidak Valid \\
\hline 82 & 3 & 3 & 4 & 4 & 4 & 4 & 17,8 & Tidak Valid \\
\hline 83 & 3 & 4 & 4 & 4 & 4 & 4 & 18,2 & Tidak Valid \\
\hline 84 & 4 & 4 & 4 & 4 & 4 & 4 & 18,6 & Tidak Valid \\
\hline
\end{tabular}

Keterangan:

$\mathrm{P} 1=$ potongan 1 , dan seterusnya.

Tot=Total panjang dari semua potongan.

Ket.: Jika lebih dari 12 meter, maka potongan dianggap tidak valid. Karena melebihi panjang besi utuh.
Untuk Potongan (P1 sampai P6), 1 adalah 1,9 meter, 2 adalah 2,2 meter, 3 adalah 2,7 meter, dan 4 adalah 3,1 meter.

\section{Mencari Pola}

Setelah mempunyai daftar semua kombinasi, maka dipilih kombinasi yang dapat dipakai. Ini kita sebut pola. Tidak semua kombinasi menjadi pola. Pemilihan adalah dengan cara eliminasi. (Guichard, 2018) Tiga cara eliminasi yang dipakai adalah sebagai berikut.

1. Panjang total harus sama atau lebih kecil dari panjang besi utuh.

Karena panjang besi utuh adalah 12 meter, maka total yang lebih dari 12 meter dianggap tidak valid. Potongan akan dieliminasi dari kanan. Misal kombinasi nomor 65 adalah 2-22-3-4-4. Eliminasi dari kanan akan menghasilkan 2-2-2-3 dengan total panjang 9,3 meter.

2. Sisa seharusnya kurang dari kebutuhan potongan terpendek.

Jika setelah dieliminasi dari kanan sisa ternyata lebih panjang dari kebutuhan terpendek, maka sisa tersebut dipotong lagi sesuai kebutuhan. Misal kombinasi nomor 65 setelah dieliminasi dari kanan menjadi 2-2-2-3 dengan total panjang 9,3 meter. Dari besi utuh 12 meter, ini menimbulkan sisa 2.7 meter. Maka sisa ini dapat dipotong lagi dengan kebutuhan 1 yaitu 1.9 meter, atau kebutuhan 2 yaitu 2.2 meter, atau kebutuhan 3 yaitu 2.7 meter. Maka kombinasi yang didapat adalah 1-2-2-2-3 atau 2-2-2-2-3 atau 2-2-2-3-3.

3. Tidak ada duplikasi.

Jika setelah langkah 1 dan 2 di atas ternyata kombinasi sudah ada, maka duplikasi akan dihilangkan.

Setelah menerapkan tiga cara eliminasi, dari contoh 84 kombinasi di atas ternyata didapat 38 pola yang akan dipakai, seperti daftar di bawah. 
Tabel 2 Pola yang dipakai

\begin{tabular}{|r|c|c|c|c|c|c|r|r|}
\hline No & P1 & P2 & P3 & P4 & P5 & P6 & Tot & Sisa \\
\hline 1 & 1 & 1 & 1 & 1 & 1 & 1 & 11,4 & 0,6 \\
\hline 2 & 1 & 1 & 1 & 1 & 1 & 2 & 11,7 & 0,3 \\
\hline 3 & 1 & 1 & 1 & 1 & 2 & 2 & 12,0 & 0 \\
\hline 4 & 1 & 1 & 1 & 1 & 3 & 0 & 10,3 & 1,7 \\
\hline 5 & 1 & 1 & 1 & 1 & 4 & 0 & 10,7 & 1,3 \\
\hline 6 & 1 & 1 & 1 & 2 & 3 & 0 & 10,6 & 1,4 \\
\hline 7 & 1 & 1 & 1 & 2 & 4 & 0 & 11,0 & 1 \\
\hline 8 & 1 & 1 & 1 & 3 & 3 & 0 & 11,1 & 0,9 \\
\hline 9 & 1 & 1 & 1 & 3 & 4 & 0 & 11,5 & 0,5 \\
\hline 10 & 1 & 1 & 1 & 4 & 4 & 0 & 11,9 & 0,1 \\
\hline 11 & 1 & 1 & 2 & 2 & 2 & 0 & 10,4 & 1,6 \\
\hline 12 & 1 & 1 & 2 & 2 & 3 & 0 & 10,9 & 1,1 \\
\hline 13 & 1 & 1 & 2 & 2 & 4 & 0 & 11,3 & 0,7 \\
\hline 14 & 1 & 1 & 2 & 3 & 3 & 0 & 11,4 & 0,6 \\
\hline 15 & 1 & 1 & 2 & 3 & 4 & 0 & 11,8 & 0,2 \\
\hline 16 & 1 & 1 & 3 & 3 & 3 & 0 & 11,9 & 0,1 \\
\hline 17 & 1 & 2 & 2 & 2 & 2 & 0 & 10,7 & 1,3 \\
\hline 18 & 1 & 2 & 2 & 2 & 3 & 0 & 11,2 & 0,8 \\
\hline 19 & 1 & 2 & 2 & 2 & 4 & 0 & 11,6 & 0,4 \\
\hline 20 & 1 & 2 & 2 & 3 & 3 & 0 & 11,7 & 0,3 \\
\hline 21 & 1 & 2 & 4 & 4 & 0 & 0 & 10,3 & 1,7 \\
\hline 22 & 1 & 3 & 3 & 4 & 0 & 0 & 10,4 & 1,6 \\
\hline 23 & 1 & 3 & 4 & 4 & 0 & 0 & 10,8 & 1,2 \\
\hline 24 & 1 & 4 & 4 & 4 & 0 & 0 & 11,2 & 0,8 \\
\hline 25 & 2 & 2 & 2 & 2 & 2 & 0 & 11,0 & 1 \\
\hline 26 & 2 & 2 & 2 & 2 & 3 & 0 & 11,5 & 0,5 \\
\hline 27 & 2 & 2 & 2 & 2 & 4 & 0 & 11,9 & 0,1 \\
\hline 28 & 2 & 2 & 2 & 3 & 3 & 0 & 12,0 & 0 \\
\hline 29 & 2 & 2 & 3 & 4 & 0 & 0 & 10,2 & 1,8 \\
\hline 30 & 2 & 2 & 4 & 4 & 0 & 0 & 10,6 & 1,4 \\
\hline 31 & 2 & 3 & 3 & 3 & 0 & 0 & 10,3 & 1,7 \\
\hline 32 & 2 & 3 & 3 & 4 & 0 & 0 & 10,7 & 1,3 \\
\hline 33 & 2 & 3 & 4 & 4 & 0 & 0 & 11,1 & 0,9 \\
\hline 34 & 2 & 4 & 4 & 4 & 0 & 0 & 11,5 & 0,5 \\
\hline 35 & 3 & 3 & 3 & 3 & 0 & 0 & 10,8 & 1,2 \\
\hline 36 & 3 & 3 & 3 & 4 & 0 & 0 & 11,2 & 0,8 \\
\hline 37 & 3 & 3 & 4 & 4 & 0 & 0 & 11,6 & 0,4 \\
\hline 38 & 3 & 4 & 4 & 4 & 0 & 0 & 12,0 & 0 \\
\hline
\end{tabular}

\section{Menghitung Sisa Pemotongan}

Ada dua macam sisa pemotongan.

Tipe 1: Setelah dipotong ternyata masih ada sisa yang terlalu pendek untuk dipotong lagi. Misal di pola nomor 1 di atas, 0,6 meter tidak dapat lagi dipotong karena lebih pendek dari kebutuhan terpendek (1.9 meter).

Tipe 2: Ketika satu kebutuhan sudah dipenuhi semua, maka pola yang mempunyai kebutuhan itu dianggap sisa. Misal kebutuhan 1,9 meter sudah dipenuhi sebanyak 200 buah. Maka ketika satu pola dipakai yang mengandung panjang kebutuhan 1,9 meter, ini dianggap sisa karena sudah tidak lagi dibutuhkan.

Sisa yang dihitung adalah tipe 1 ditambah tipe 2. Untuk optimasi, dicari sisa yang minimum, yaitu jumlah sisa yang paling kecil.

\section{Langkah Pengulangan}

Untuk tiap langkah pengulangan, diperiksa sisa terkecil dari semua pola. Kemudian pola dengan sisa minimum akan dipakai. Jumlah kebutuhan yang sudah dipotong bertambah sesuai pola yang dipakai.

Contoh tabel pola di atas, pola nomor 3 dengan sisa 0 adalah pola dengan sisa terkecil. Pola ini yang dipakai di pengulangan pertama. Kemudian larik pemenuhan kebutuhan akan diubah sesuai pola nomor 3 .

Tabel 3 Larik Pemenuhan Kebutuhan

\begin{tabular}{|c|c|c|c|}
\hline Item & Panjang & Banyaknya & Sudah dipotong \\
\hline 1 & $1.9 \mathrm{~m}$ & 200 & 4 \\
\hline 2 & $2.2 \mathrm{~m}$ & 150 & 2 \\
\hline 3 & $2.7 \mathrm{~m}$ & 100 & 0 \\
\hline 4 & $3.1 \mathrm{~m}$ & 200 & 0 \\
\hline
\end{tabular}

Larik pemenuhan kebutuhan ini akan dilihat setiap kali melakukan pengulangan untuk melihat kebutuhan mana yang sudah lengkap terpenuhi.

Langkah selanjutnya adalah mengambil besi berikutnya, dan dicari pola yang memberikan sisa terkecil dari semua pola yang ada. Pengulangan akan dihentikan jika semua kebutuhan sudah dipenuhi.

Langkah iterasi dapat digambarkan seperti di bawah ini.

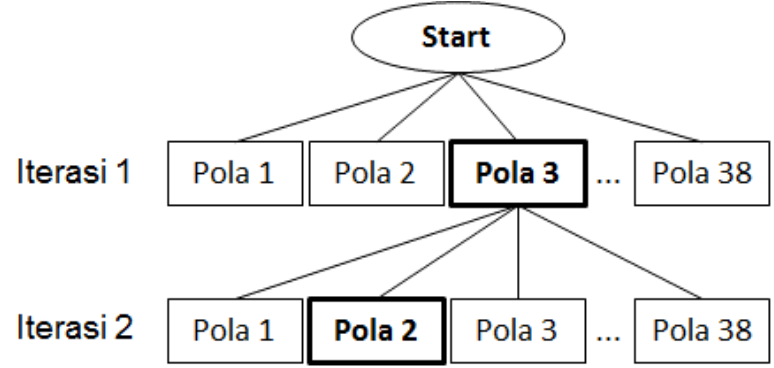

Gambar 1 Langkah pengulangan

Pada contoh di atas, pada pengulangan pertama Pola 3 adalah pola dengan sisa terkecil. Ini diambil sebagai pola pemotongan besi 1 .

Pada langkah kedua, Pola 2 ternyata memberi sisa terkecil. Maka pola 2 dipakai untuk pemotongan besi kedua. Demikian seterusnya.

Pada Pencarian Rakus, hanya pola yang sudah dipilih di langkah pertama akan diikuti. 
Kemungkinan pola ini tidak optimal tidak didiskusikan di Pencarian Rakus.

\section{Solusi Optimal}

Dalam tiap langkah pengulangan, kemungkinan ada lebih dari satu pola yang optimal. Dalam 38 pola di atas, kita dapat melihat ada tiga pola yang menghasilkan sisa 0 meter, yaitu Pola 3, Pola 28 dan Pola 38. Ketiganya adalah pola optimal. Tapi dalam Pencarian Rakus kita hanya akan memakai satu pola saja. Pola yang lain diabaikan meski pun sama-sama optimal.

Pola yang diabaikan ini kemungkinan bisa mendapatkan solusi global yang lebih optimal, karena adanya sisa tipe 2 yang berbeda untuk langkah iterasi selanjutnya.

Demikian juga pola yang kurang optimal di langkah pertama, kemungkinan bisa mendapatkan solusi global yang lebih optimal di langkahlangkah selanjutnya.

\section{Implementasi Pencarian Rakus}

Pemrograman dilakukan dengan bahasa $\mathrm{C}++$ di lingkungan desktop Microsoft Windows. (Kirch-prinz \& Prinz, 2002) Compiler yang dipakai adalah Dev-C++.

Hasil yang didapat dengan beberapa kebutuhan adalah sebagai berikut.

$\begin{array}{lcc}\begin{array}{l}\text { Kebutuhan } 1 \\ \text { Item }\end{array} & \text { Panjang } & \text { Banyaknya } \\ 1 & 1,9 \mathrm{~m} & 150 \\ 2 & 2,2 \mathrm{~m} & 120 \\ 3 & 2,7 \mathrm{~m} & 200 \\ 4 & 3,1 \mathrm{~m} & 100 \\ & \\ \text { Besi terpakai : } 120 \text { batang } \\ \text { Sisa terbuang : } 41 \text { meter } \\ \text { Persen } & : 2.8 \%\end{array}$

\section{Kebutuhan 2}

$\begin{array}{lll}\text { Item } & \text { Panjang } & \text { Banyaknya } \\ 1 & 1,9 \mathrm{~m} & 1300 \\ 2 & 2,2 \mathrm{~m} & 1250 \\ 3 & 2,7 \mathrm{~m} & 1320 \\ 4 & 3,1 \mathrm{~m} & 1270\end{array}$

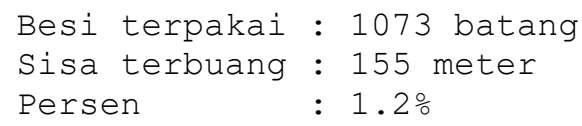

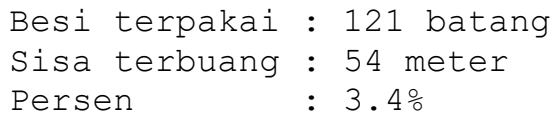

Di atas adalah hasil dari beberapa contoh kebutuhan besi yang dipakai dalam konstruksi. Dalam percobaan yang dilakukan dengan 10 data kebutuhan, sisa yang dihasilkan bervariasi antara $0,5 \%$ sampai $6,9 \%$.

\section{Kesimpulan}

Algoritma Pencarian Rakus tidak menjamin mendapatkan solusi global optimal. Algoritma ini akan mendapatkan solusi lokal optimal. Ini bisa jadi adalah solusi global optimal, bisa juga bukan. Untuk memastikan mendapatkan solusi global optimal, seluruh pola harus terus dilacak sampai akhir kemudian dicari mana yang paling optimal. Ini adalah metode Brute Force. Cara ini akan memakan banyak resource karena banyaknya kemungkinan akan meningkat secara eksponensial seiring dengan banyaknya variabel.

Algoritma Pencarian Rakus tetap banyak dipakai untuk mencari solusi yang mendekati optimal karena algoritma ini efektif dan hasilnya cukup baik.

\section{Referensi}

Abuhassan, I. A. O., \& Nasereddin, H. H. O. (2011). Cutting Stock Problem: Solution Behaviors. 6(4), 429-433. Retrieved from https://www.researchgate.net/publication/28 1120697_CUTTING_STOCK_PROBLEM_ SOLUTION_BEHAVIORS

Brualdi, R. A. (2010). Introductory Combinatorics. In Pearson Education, Inc. https://doi.org/10.2307/2320280

Feo, T. A., \& Resende, M. G. C. (1995). Greedy Randomized Adaptive Search Procedures. Journal of Global Optimization, 6(2), 109134. https://doi.org/10.1007/BF01096763

Guichard, D. (2018). An Introduction to Combinatorics and Graph. Creative Commons.

Kirch-prinz, U., \& Prinz, P. (2002). A Complete Guide to Programming in $C++$ (1st ed.). Sudbury, MA: Jones And Bartlett Publishers.

Malik, A., Sharma, A., \& Saroha, V. (2013). Greedy Algorithm. International Journal of Scientific and Research Publications, 3(8), 1-4. Retrieved from http://xlinux.nist.gov/dads//HTML/greedyalg o.html

Subhadra, A. (2016). Greedy Algorithms: 
Analysis, Design \& Applications.

International Journal of Informative \&

Futuristic Research, 3(5), 1749-1764.

Wilt, C., Thayer, J., \& Ruml, W. (2010). A comparison of greedy search algorithms. Proceedings of the 3rd Annual Symposium on Combinatorial Search, SoCS 2010, (July 2010), 129-136. 